\title{
Trends in objectively measured and perceived mental health and use of mental health services: a population-based study in Ontario, 2002-2014
}

\author{
Maria Chiu PhD, Abigail Amartey MPH, Xuesong Wang MSc, Simone Vigod MD MSc, Paul Kurdyak MD PhD
}

Cite as: CMAJ 2020 March 30;192:E329-37. doi: 10.1503/cmaj.190603

See related article at www.cmaj.ca/lookup/doi/10.1503/cmaj.200156

\begin{abstract}
BACKGROUND: Mental illness is widely perceived to be more of a public health concern now than in the past; however, it is unclear whether this perception is due to an increase in the prevalence of mental illness, an increase in helpseeking behaviours or both. We examined temporal trends in use of mental health services as well as objectively measured and perceived mental health.

Statistical Manual of Mental Disorders, 4th Edition, and International Classification of Diseases, 10th Revision) and pastmonth psychological distress (Kessler Psychological Distress Scale-6 score $\geq 8$ ) and perceived, self-rated mental health. We also examined use of mental health services, including service use among those with a need for mental health care.
\end{abstract}

METHODS: We conducted a repeat cross-sectional study of Ontario residents who participated in Statistics Canada's Canadian Community Health Survey (2002-2014). We assessed temporal trends in objectively measured past-year major depressive episode (based on criteria of the Diagnostic and
RESULTS: A total of 260090 survey participants were included. The age- and sex-standardized prevalence of a major depressive episode $(4.8 \%, 95 \%$ confidence interval $[\mathrm{Cl}] 4.2 \%-5.3 \%$ in $2002 \mathrm{v}$. $4.9 \%, 95 \% \mathrm{Cl} 4.2 \%-5.7 \%$ in $2012 ; p=0.9$ ) and psychological distress $(7.0 \%, 95 \% \mathrm{Cl}$ $6.3 \%-7.6 \%$ in 2002 v. $6.5 \%, 95 \%$ Cl $5.7 \%$ -
$7.5 \%$ in 2012; $p=0.4$ ) did not change significantly over time. However, selfrated fair or poor mental health status increased from $4.9 \%$ in 2003-2005 to $6.5 \%$ in $2011-2014$ ( $\left.p_{\text {trend }}<0.001\right)$, as did the use of mental health services $(7.2 \%$ to $\left.12.8 \%, p_{\text {trend }}<0.001\right)$. The percentage of individuals who had subjective or objectively measured mental health problems and did not access mental health services decreased significantly over time.

INTERPRETATION: Given the stable prevalence of objectively measured psychiatric symptoms, the increase in use of mental health services appears to be, at least partly, explained by an increase in perceived poor mental health and help-seeking behaviours.
M ental illness is widely perceived to be more of a public health issue now than in the past. Developed countries have reported increases of up to $40 \%$ in the use of acute care and ambulatory mental health services in the past 2 decades. ${ }^{1-5}$ However, the prevalence of psychiatric disorders has remained stable over time in Canada, ${ }^{6,7}$ in the United States ${ }^{5,8}$ and globally. ${ }^{9-11}$ The stability in prevalence amid rising use of mental health services suggests that public perceptions and attitudes toward mental illness may have shifted.

Major depression and psychological distress represent 2 of the most common mental health problems worldwide. Major depression, which includes symptoms such as depressed mood, diminished interests or pleasure, and feelings of worthlessness, ${ }^{12}$ has a reported lifetime prevalence of $11.3 \%$ in Can- ada. ${ }^{13}$ Psychological distress is more prevalent and is characterized by a combination of depressive and anxiety symptoms that do not meet the criteria for a diagnosis of major depressive disorder or anxiety-related disorder. ${ }^{14}$ Measuring trends in these objectively measured conditions along with trends in perceived mental health - a subjective assessment of one's overall mental health status - can help to show whether attitudes toward mental health are changing. Although perceived mental health cannot directly correspond to objectively measured mental health conditions, evidence has shown increased service use among those self-reporting mental health issues, ${ }^{15-20}$ indicating that this measure can play an important role in explaining changing patterns of mental health service use. To our knowledge, no previous study has concurrently 
examined trends in objectively measured and self-reported mental health status, along with use of mental health services in a population-based sample.

We examined temporal trends in both objectively measured and perceived mental health, and self-reported use of mental health services in a repeat cross-sectional study in Ontario, Canada, from 2002 to 2014. We also examined whether there were any temporal changes in the proportion of individuals with objectively measured or subjective mental health issues who were not receiving care. We hypothesized that objectively measured need for mental health care would be stable over time but that, because of increased awareness and reduced stigma, we would observe a rise in self-rated poor mental health and use of mental health services.

\section{Methods}

\section{Data sources and study population}

We used data from Statistics Canada's Canadian Community Health Survey (CCHS) Mental Health and Well-being Cycle 1.2 (2002) and the CCHS - Mental Health (2012) on Ontario residents aged 15 years and older to capture objectively measured psychiatric diagnoses. We used the CCHS survey cycles 2.1 (2003) and 3.1 (2005) and annual cycles from 2007 to 2014 to capture subjective need for mental health care (i.e., self-rated mental health) and self-reported use of mental health services among Ontario residents aged 12 years and older. Details about the survey methodology are described elsewhere. ${ }^{21,22}$ Briefly, the CCHS is a cross-sectional survey that uses a consistent method of multistage stratified cluster sampling to collect sociodemographic and health-related information from a representative sample of people in private dwellings, with a response rate ranging from $63 \%$ to $78.5 \%$. Individuals living on Crown lands, residents of Indigenous communities, those living in health institutions, fulltime members of the Canadian Forces, and those living in some remote areas of Ontario were excluded from the survey.

\section{Study variables}

We analyzed 2 objectively measured mental health indicators that have high population prevalence and were consistently collected in the 2002 and 2012 surveys: past-year Diagnostic and Statistical Manual of Mental Disorders, 4th Edition, and International Classification of Diseases, 10th Revision, criteria for major depressive episode (World Health Organization World Mental Health Composite International Diagnostic Interview), ${ }^{23}$ and past-month psychological distress (score of $\geq 8$ on the Kessler Psychological Distress Scale-6 $6^{24-26}$ among those who did not have a major depressive episode). Subjective need for mental health care was examined by assessing fair or poor self-rated mental health status from 2003 to 2014. We also examined self-reported physician-diagnosed mood or anxiety disorder and use of mental health services, defined as selfreported past-year visit to, or telephone conversation with, a health care professional for emotional or mental health (20032014). Last, we calculated the proportion of individuals with past-year major depressive episode, past-month psychological distress, or current self-reported fair or poor mental health status who did not report any use of mental health services in the year before the survey.

A list of the full CCHS questions analyzed in this study, as well as the full definitions and criteria used to identify those with major depressive episode and psychological distress can be found in Appendix 1, Supplemental Table S1, available at www. cmaj.ca/lookup/suppl/doi:10.1503/cmaj.190603/-/DC1.

\section{Statistical analysis}

We described the baseline sociodemographic characteristics of the sample, and calculated age- and sex-standardized prevalence of each mental health variable using the direct standardization method and the Ontario component of the 2006 Canadian Census as the standard population.

For major depressive episode, psychological distress and health service use among those with major depressive episode and psychological distress, we compared trends over time by calculating percent change in the 2002 versus 2012 prevalence estimates, and bootstrap methods were used to estimate $p$ values. For perceived mental health and self-reported use of mental health services, to ensure adequate sample size, survey cycles were combined using the pooled approach without rescaling of sampling weights, ${ }^{27,28}$ and we calculated standardized prevalence estimates across 3 periods: 2003-2005, 2007-2010 and 2011-2014. Temporal trends were assessed across the 3 time periods using $p$ values derived from age- and sex-adjusted Poisson regression models (denoted as $p_{\text {trend }}$ in the paper).

To examine whether trends differed by sociodemographic characteristics, we compared the above trends across sex, age (12-24, 25-64 and $\geq 65 \mathrm{yr}$ ), annual household income ( $<\$ 30000, \$ 30000$ to $\$ 59999$, and $\geq \$ 60000)$, and educational attainment (high school graduation or less $v$. more than high school graduation).

Statistical analyses were performed using SAS version 9.4 statistical software, and all analyses were weighted by Statistics Canada's sample weights to account for the complex survey sampling design and to improve generalizability of the estimates. Bootstrap methods were used to test significance, and the $95 \%$ confidence interval $(\mathrm{Cl})$ was defined as the 2.5 th and 97.5th percentile of the 500 bootstrap rates or the natural logarithm of rate ratios (for percent changes). Standardized differences were estimated and $p$ values were derived from the standard z-test, in which the rate or the logarithm of the rate ratio was divided by the standard deviation of this statistic across the 500 bootstrap samples. All tests were 2 -sided, and $p$ values (including $p_{\text {trend }}$ values) less than 0.05 were considered significant. Missing values were excluded when calculating prevalence estimates for mental health-related factors and service use variables ( $\leq 2.5 \%$ missing for all variables; Appendix 1 ).

\section{Ethics approval}

Informed consent was obtained by Statistics Canada from all study participants. The use of data in this project was authorized under section 45 of Ontario's Personal Health Information Protection Act, which does not require review by a research ethics board. 
Table 1: Trends in prevalence of sociodemographic characteristics over time in Ontario, Canada, 2002-2014*

\begin{tabular}{|c|c|c|c|c|c|c|c|c|}
\hline \multirow[b]{3}{*}{ Characteristic } & \multicolumn{3}{|c|}{ CCHS mental health surveys $\dagger$} & \multicolumn{5}{|c|}{ CCHS annual surveys } \\
\hline & \multirow{2}{*}{$\begin{array}{c}2002 \\
n=12376 \\
\% \ddagger\end{array}$} & \multicolumn{2}{|c|}{$\begin{array}{c}2012 \\
n=5083\end{array}$} & \multirow{2}{*}{$\begin{array}{c}2003-2005 \\
n=79993 \\
\% \ddagger\end{array}$} & \multicolumn{2}{|c|}{$\begin{array}{c}2007-2010 \\
n=82203\end{array}$} & \multicolumn{2}{|c|}{$\begin{array}{c}2011-2014 \\
n=80435\end{array}$} \\
\hline & & $\% \ddagger$ & Std. diff. & & $\% \ddagger$ & Std. diff. & $\% \ddagger$ & Std. diff. \\
\hline Age, yr, mean & 43.7 & 45.5 & 0.09 & 42.5 & 43.3 & 0.05 & 44.3 & 0.10 \\
\hline \multicolumn{9}{|l|}{ Age group, yr } \\
\hline $12-24$ & 16.3 & 16.2 & 0.004 & 21.0 & 20.2 & 0.02 & 19.7 & 0.03 \\
\hline $25-64$ & 68.8 & 66.9 & 0.04 & 64.7 & 64.8 & 0.001 & 63.7 & 0.02 \\
\hline$\geq 65$ & 14.9 & 16.9 & 0.06 & 14.3 & 15.0 & 0.02 & 16.6 & 0.06 \\
\hline Sex, male & 49.0 & 48.9 & 0.002 & 49.1 & 49.1 & 0.002 & 48.9 & 0.004 \\
\hline \multicolumn{9}{|l|}{ Marital status } \\
\hline Divorced or separated & 6.8 & 8.4 & 0.06 & 6.2 & 7.1 & 0.04 & 7.4 & 0.05 \\
\hline Widowed & 5.2 & 4.8 & 0.02 & 4.8 & 4.7 & 0.004 & 4.7 & 0.005 \\
\hline Single, never married & 25.0 & 27.8 & 0.06 & 30.1 & 30.0 & 0.00 & 30.8 & 0.01 \\
\hline Common-law or married & 63.0 & 59.0 & 0.08 & 59.0 & 58.3 & 0.01 & 57.1 & 0.04 \\
\hline \multicolumn{9}{|l|}{ Highest level of education } \\
\hline High school graduation or less & 43.5 & 34.2 & 0.2 & 41.3 & 37.7 & 0.08 & 37.9 & 0.08 \\
\hline More than high school graduation & 56.5 & 65.8 & 0.2 & 58.7 & 62.3 & 0.05 & 62.1 & 0.06 \\
\hline \multicolumn{9}{|l|}{ Annual household income, \$ } \\
\hline Mean income & 70659.5 & 81015.4 & 0.2 & 77555.4 & 84318.8 & 0.1 & 88170.2 & 0.08 \\
\hline$<30000$ & 17.9 & 15.0 & 0.03 & 15.8 & 15.1 & 0.03 & 15.5 & 0.05 \\
\hline 30000 to 59999 & 31.0 & 27.9 & 0.007 & 27.6 & 25.3 & 0.06 & 26.1 & 0.06 \\
\hline$\geq 60000$ & 51.1 & 57.1 & 0.2 & 56.6 & 59.7 & 0.02 & 58.4 & 0.2 \\
\hline Living in urban area & 83.2 & 84.8 & 0.04 & 85.8 & 85.2 & 0.02 & 84.6 & 0.03 \\
\hline $\begin{array}{l}\text { Note: CCHS = Canadian Community Health Su } \\
\text { *Standardized differences were calculated to } \\
\text { †Sociodemographic characteristics were deri } \\
\text { Source: Data were derived from the Ontario c } \\
\text { fUnless noted otherwise. }\end{array}$ & $\begin{array}{l}\text { diff. = standard } \\
2002 \text { estimates } \\
\text { he CCHS Menta } \\
\text { s of Statistics C }\end{array}$ & $\begin{array}{l}\text { difference } \\
2012 \text { estim } \\
\text { lth and We } \\
\text { a's CCHS. }\end{array}$ & $\begin{array}{l}\text { and to con } \\
\text { eing Cycle } 1 \\
\text { nates were }\end{array}$ & $\begin{array}{l}2007-2010 \text { an } \\
02 \text { ) and the } C C \\
\text { ted by the sur }\end{array}$ & $\begin{array}{l}1-2014 \text { est } \\
\text { Mental He } \\
\text { ample wei }\end{array}$ & $\begin{array}{l}\text { ates with } 2 \text { (2012) sur } \\
\text { (2012 }\end{array}$ & .005 estimat & \\
\hline
\end{tabular}

\section{Results}

\section{Study population and demographic characteristics}

Sociodemographic characteristics of the participants in the CCHS Mental Health surveys $(n=12376$ in 2002 and $n=5083$ in 2012) were similar to those in the CCHS surveys from 2003 to $2014(n=242631)$; the mean age ranged from 42.5 years to 45.5 years, and $49.0 \%$ of the population was male (Table 1 ). Most respondents had more than high school education $(56.5 \%-$ $65.8 \%)$, and most had an average annual household income of $\$ 60000$ or more.

\section{Mental health status and use of mental health services} Neither the overall prevalence of past-year major depressive episode nor past-month psychological distress changed significantly over time from 2002 to 2012 (past-year major depressive episode: $4.8 \%, 95 \% \mathrm{Cl} 4.2-5.3$ v. $4.9 \%, 95 \% \mathrm{Cl} 4.2-5.7 ; p=0.9$; past-month psychological distress: $7.0 \%, 95 \% \mathrm{Cl} 6.3-7.6$ v. $6.5 \%, 95 \% \mathrm{Cl} 5.7-$ 7.5; $p=0.4)$. In contrast, the prevalence of self-reported need for mental health care rose from $4.9 \%(95 \% \mathrm{Cl} 4.7-5.2)$ in 2003-2005 to $6.5 \%(95 \% \mathrm{Cl} 6.2-6.8)$ in $2011-2014$ ( $p_{\text {trend }}<0.001$ ), as did physician-diagnosed mood disorders and physician-diagnosed anxiety disorders. In particular, the prevalence of self-reported physician-diagnosed mood disorder in 2011-2014 was 8.0\%, 1.6fold higher than the measured prevalence of major depressive episode $(4.9 \%)$ in 2012. Use of mental health services increased significantly from $7.2 \%(95 \% \mathrm{Cl} 6.9-7.4)$ in $2003-2005$ to $12.8 \%$ $(95 \% \mathrm{Cl} 12.4-13.3)$ in 2011-2014 ( $p_{\text {trend }}<0.001$ ) (Figure 1 and Appendix 1). These trends were consistent across sex and age groups (Figure 1 and Table 2).

\section{Use of mental health services among those in need}

Overall, use of mental health services among those reporting mental health issues increased over time (Figure 2; Appendix 1). For participants with past-year major depressive episode, the percentage of individuals not using mental health services was $48.8 \%(95 \% \mathrm{Cl} 42.9-53.4)$ in 2002 , decreasing to $35.6 \%(95 \% \mathrm{Cl}$ $27.8-41.3)$ in $2012(p=0.01)$. The proportion of individuals with major depressive episode not using mental health services decreased over time in the group younger than 65 years but 


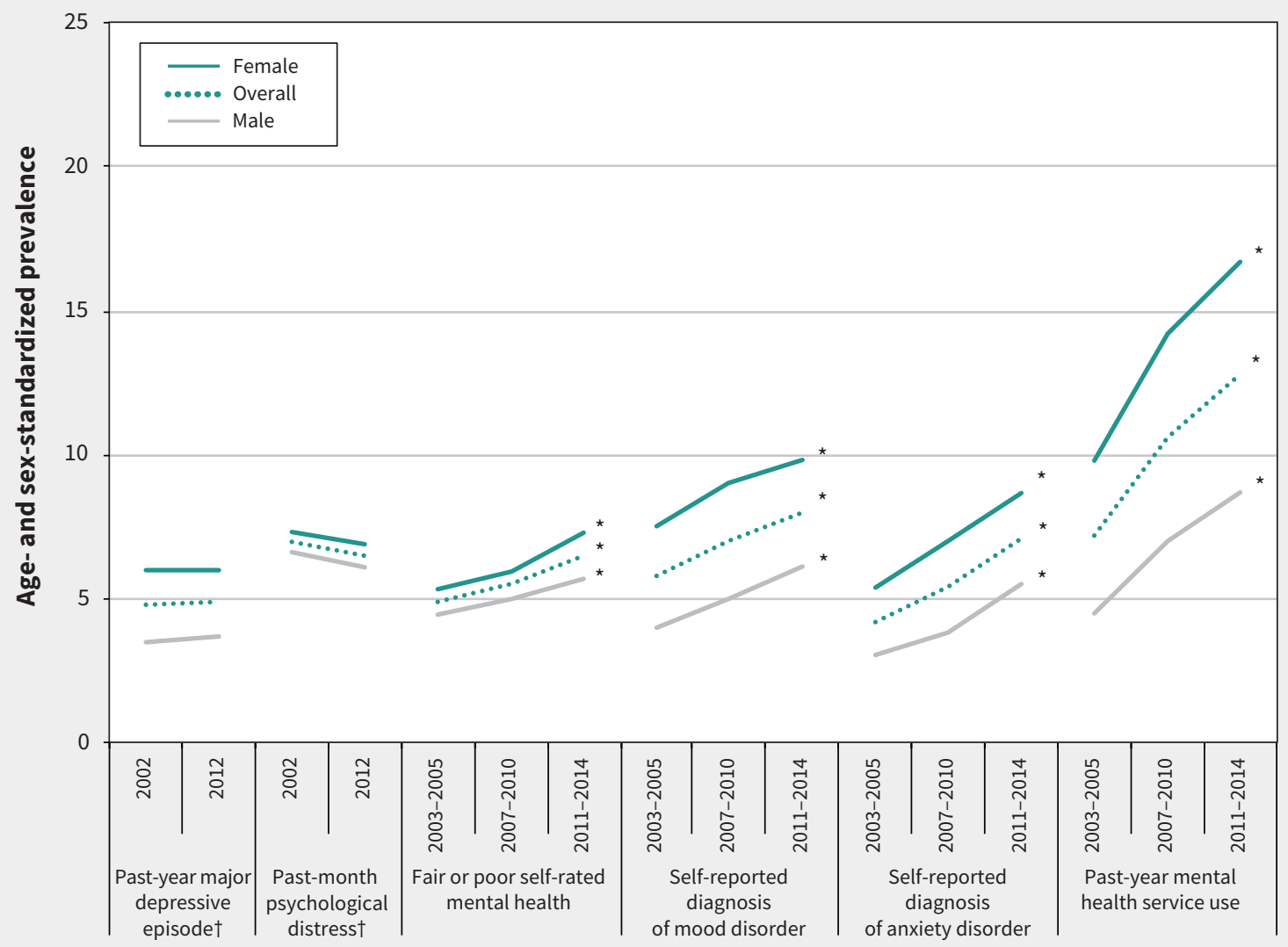

Figure 1: Trends in the prevalence of mental health status and service use per 100 population, overall and by sex, in Ontario, 2002-2014. Source: Data were derived from the Ontario components of Statistics Canada's Canadian Community Health Surveys (CCHS). Estimates were age- and sex-standardized (sexspecific estimates were age-standardized) to the the Ontario component of the 2006 Canadian Census population using age groups 12-14 years followed by 5 -year age categories and were weighted by the survey sample weight. ${ }^{*}$ Indicates that the change in prevalence over time was significant $(p<0.05)$. TVariable was derived from the CCHS Mental Health and Well-being Cycle 1.2 (2002) and the CCHS - Mental Health (2012) surveys. All other variables were derived from the CCHS.1 annual surveys.

remained stable in the group aged 65 years and older (Figure 2). Among participants with past-month psychological distress and fair or poor self-rated mental health, the proportion not accessing mental health services decreased significantly over time.

Stratified analyses were generally consistent with those of the main analysis, with some exceptions. Overall, the prevalence of almost all outcome measures (Figure 2; Appendix 1, Supplemental Tables S3 and S4) was highest for the groups with the lowest income and educational attainment. For objectively measured need for mental health care, major depressive episode increased significantly among those in the middle-income group (Appendix 1). Individuals with a lower household income had a greater increase in rates of fair or poor self-rated mental health over time than individuals with higher household income (Figure 3, Appendix 1).

\section{Interpretation}

We found that despite a stable prevalence of major depressive episode and psychological distress over an 11-year period, the proportion of Ontario residents self-reporting poor mental health rose significantly, with a greater proportion of people accessing mental health services. Of note, the prevalence of self-reported physiciandiagnosed mood disorder in 2011-2014 was 1.6-fold higher than the measured prevalence of major depressive episode in 2012, which suggests that many more people describe themselves as depressed than are assessed as depressed by a validated instrument. The percentage of individuals with both objective and subjective mental health issues who did not access mental health services in the past year declined over time. The contrast in prevalence trends seen between objective and self-reported psychiatric conditions may be a by-product of increasing use of the mental health system, which can increase the possibility of one receiving a psychiatric diagnosis from a health care professional, including evidence of overdiagnosis in clinical settings. ${ }^{29-32}$

Our findings of a stable prevalence in major depressive episode and psychological distress are consistent with those of studies of populations in Canada, the US, the United Kingdom and the Netherlands, which have reported stable prevalence rates of major depressive episodes, psychological distress and other psychiatric disorders. ${ }^{5-8,10,11}$ Although we found some indication that objectively measured major depressive episode might be increasing in the groups with the lowest income and educational attainment, 


\begin{tabular}{|c|c|c|c|c|}
\hline \multirow[b]{2}{*}{ Characteristic } & \multirow[b]{2}{*}{ Year } & \multicolumn{3}{|c|}{$\%(95 \% \mathrm{Cl}) \ddagger$} \\
\hline & & Age 12-24 yr & Age 25-64 yr & Age $\geq 65$ yr \\
\hline \multirow[t]{3}{*}{ Past-year major depressive episode } & 2002 & $7.2(5.7-8.9)$ & $4.9(4.3-5.5)$ & $1.8(1.2-2.3)$ \\
\hline & 2012 & $6.5(4.6-8.6)$ & $5.1(4.1-6.2)$ & $1.6(1-2.3)$ \\
\hline & $p$ value & 0.6 & 0.8 & 0.7 \\
\hline \multirow{3}{*}{ Past-month psychological distress } & 2002 & $10.1(8.4-11.8)$ & $6.5(5.7-7.3)$ & $5.2(4.1-6.5)$ \\
\hline & 2012 & $8.4(6.5-10.5)$ & $6.3(5.3-7.5)$ & $5.2(3.7-7.1)$ \\
\hline & $p$ value & 0.2 & 0.8 & $>0.9$ \\
\hline \multirow[t]{4}{*}{ Fair or poor self-rated mental health } & $2003-2005$ & $3.8(3.4-4.2)$ & $5.2(4.9-5.5)$ & $5.2(4.6-5.7)$ \\
\hline & $2007-2010$ & $4.0(3.5-4.5)$ & $6.0(5.7-6.5)$ & $5.4(4.9-6.0)$ \\
\hline & 2011-2014 & $5.7(5.1-6.3)$ & $7.0(6.6-7.4)$ & $5.9(5.4-6.4)$ \\
\hline & $p$ value & $<0.001$ & $<0.001$ & $<0.001$ \\
\hline \multirow[t]{4}{*}{ Self-reported diagnosis of mood disorder } & 2003-2005 & $4.0(3.6-4.4)$ & $6.7(6.4-7.0)$ & $4.6(4.1-5.0)$ \\
\hline & $2007-2010$ & $4.6(4.1-5.1)$ & $8.0(7.7-8.5)$ & $6.4(6.0-6.9)$ \\
\hline & 2011-2014 & $5.4(4.9-5.9)$ & $9.2(8.8-9.7)$ & $7.1(6.6-7.7)$ \\
\hline & $p$ value & 0.009 & $<0.001$ & $<0.001$ \\
\hline \multirow[t]{4}{*}{ Self-reported diagnosis of anxiety disorder } & 2003-2005 & $3.6(3.2-4.0)$ & $4.8(4.5-5.0)$ & $3.0(2.7-3.4)$ \\
\hline & $2007-2010$ & $5.1(4.7-5.7)$ & $6.0(5.7-6.4)$ & $3.7(3.4-4.1)$ \\
\hline & 2011-2014 & $7.9(7.2-8.6)$ & $7.5(7.0-7.9)$ & $4.8(4.3-5.3)$ \\
\hline & $p$ value & $<0.001$ & $<0.001$ & $<0.001$ \\
\hline \multirow[t]{4}{*}{ Past-year use of mental health services } & $2003-2005$ & $5.0(4.6-5.5)$ & $8.9(8.5-9.3)$ & $2.9(2.5-3.3)$ \\
\hline & $2007-2010$ & $8.4(7.8-9.0)$ & $12.6(12.2-13.1)$ & $5.6(5.2-6.1)$ \\
\hline & 2011-2014 & $11.7(10.8-12.6)$ & $14.4(13.9-15.1)$ & $7.3(6.7-7.9)$ \\
\hline & $p$ value & $<0.001$ & $<0.001$ & $<0.001$ \\
\hline \multicolumn{5}{|c|}{ 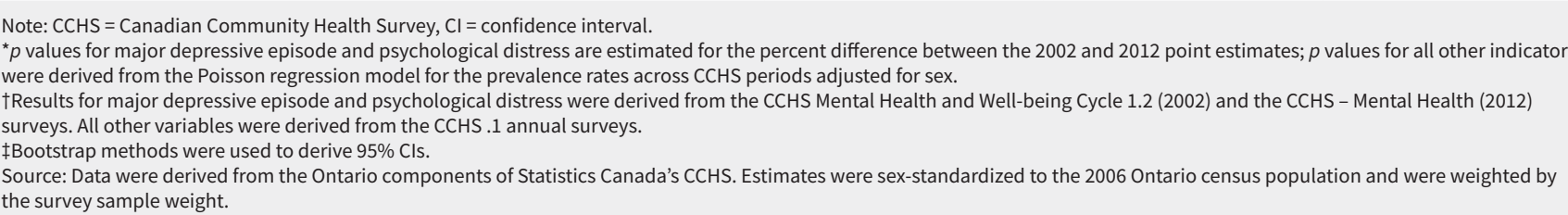 } \\
\hline
\end{tabular}

this finding was not significant. Future studies using larger samples should investigate whether increasing morbidity of depressive symptoms might explain the significant rise in fair or poor self-rated mental health and use of mental health services among these socioeconomically disadvantaged populations.

One possible explanation for the increasing use of mental health services may be improvements in access and availability. Several jurisdictions, including Canada, ${ }^{24,25}$ Australia $^{33}$ and the UK, ${ }^{34}$ have implemented strategies or policies over the past decade focusing on mental health funding, services and supports. Furthermore, evidence suggests that population perceptions toward mental illness are changing. Our findings are consistent with those of earlier studies that found a greater tendency for individuals to self-report poor mental health and anxiety disorders. ${ }^{5,35}$

Although stigma and discrimination continue to be barriers when accessing mental health services, our hypothesis of changing perceptions and attitudinal shifts toward mental illness has been supported by some past studies. ${ }^{22,23}$ For example, one US study found that, compared with respondents in a 1990-1992 survey, individuals responding to a 2001-2003 survey were more willing to seek professional help for mental health, were more comfortable talking to a health professional about their problems, and were less embarrassed if others found out. ${ }^{36-38}$ The aforementioned findings may be related to decreased stigma, which has been shown to lead to improved attitudes toward mental illness. ${ }^{39-41}$ For example, Evans-Lacko and colleagues found that European countries with higher rates of help-seeking behaviours and use of mental health services tended to have lower rates of self-stigma and perceived discrimination, ${ }^{39}$ suggesting generalizability of our findings to populations living in other jurisdictions. ${ }^{35,42}$

The stability in objectively measured psychiatric conditions taken together with worsening self-perceived mental health and increasing use of mental health services has an impact on unmet need for mental health care, which has historically been very high. ${ }^{43-47}$ Similar to 
A)

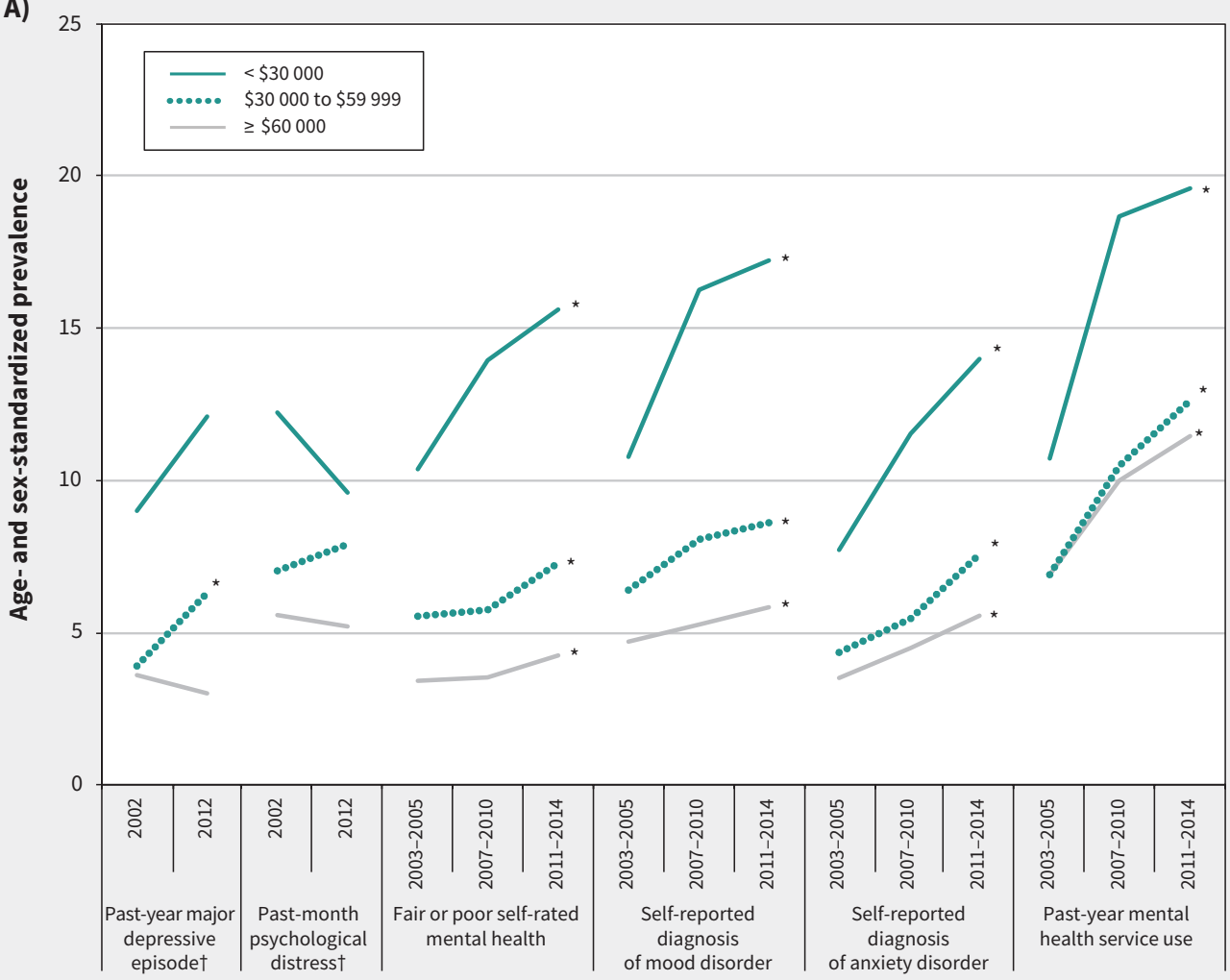

B)

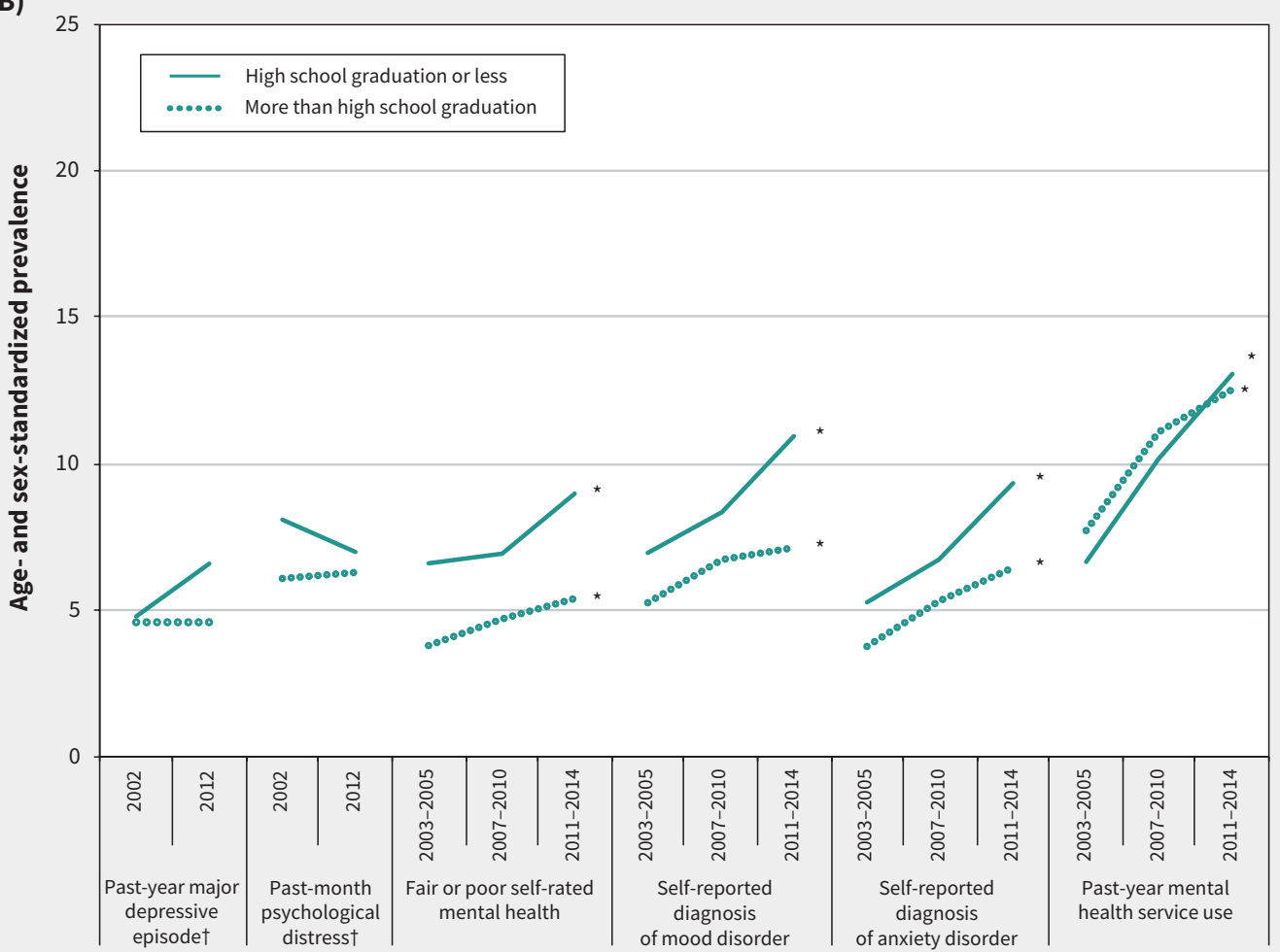

Figure 2: Trends in the prevalence of mental health status and service use over time per 100 population, by (A) annual household income and (B) educational attainment, in Ontario, 2002-2014. Source: Data were derived from the Ontario components of Statistics Canada's Canadian Community Health Surveys (CCHS). Estimates were age- and sex-standardized to the Ontario component of the 2006 Canadian Census population using age groups 12-14 years followed by 5-year age categories and were weighted by the survey sample weight. *Indicates that the change in prevalence over time was significant $(p<0.05)$. †Variable was derived from the CCHS Mental Health and Well-being Cycle 1.2 (2002) and the CCHS - Mental Health (2012) surveys. All other variables were derived from the CCHS .1 annual surveys. 
A)

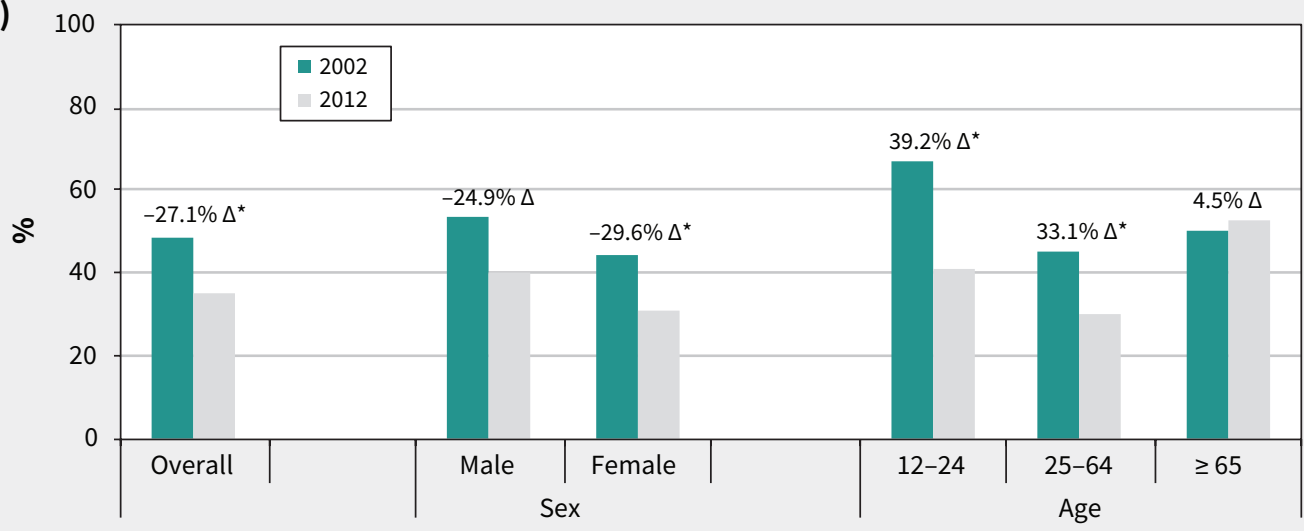

B)

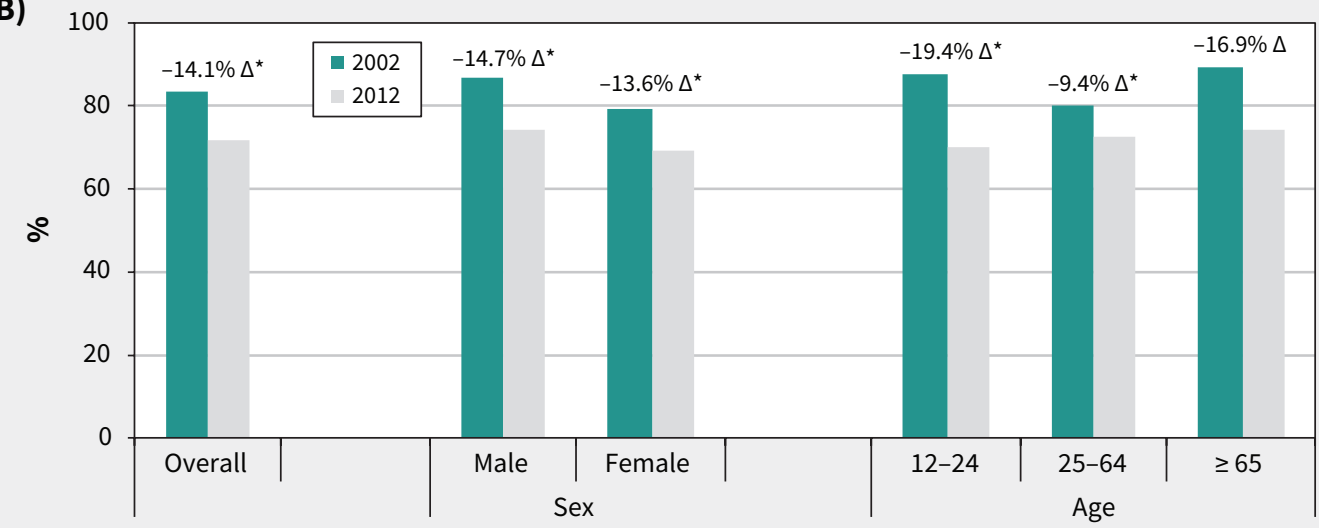

C)

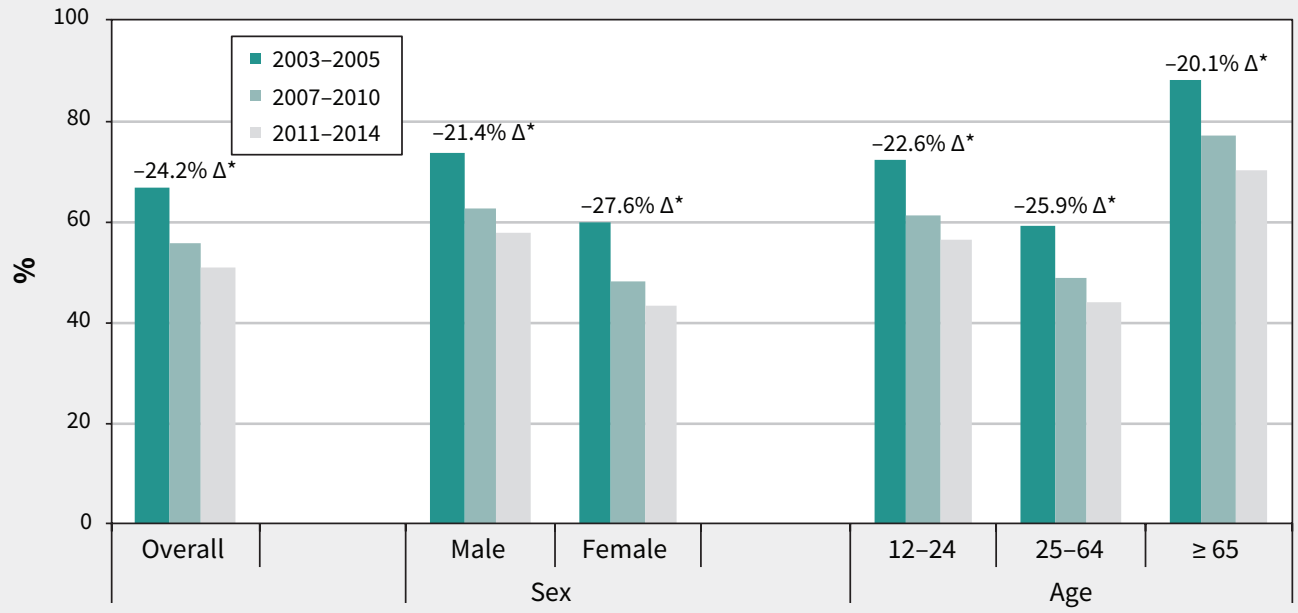

Figure 3: Percentage of individuals with (A) major depressive episode, (B) psychological distress, and (C) fair or poor self-rated mental health who did not access mental health care in the past year, overall and by age and sex, in Ontario, 2002-2014. Source: Data were derived from the Ontario components of Statistics Canada's Canadian Community Health Surveys (CCHS). Estimates were age- and sex-standardized to the Ontario component of the 2006 Canadian Census population using age groups 12-14 years followed by 5-year age categories and were weighted by the survey sample weight. Results for major depressive episode and psychological distress were derived from the CCHS Mental Health and Well-being Cycle 1.2 (2002) and the CCHS - Mental Health (2012) surveys. Results for fair or poor self-rated mental health were derived from the CCHS .1 annual surveys. ${ }^{*}$ Indicates that the change in prevalence over time was significant $(p<0.05)$. Specific $p$ values are given in Appendix 1, Supplemental Table S5. 
our findings, Kessler and colleagues ${ }^{8}$ found a significant increase from 1990 to 2003 in use of mental health services among individuals reporting moderate or mild mental illness. Furthermore, an Australian study found a decrease in the proportion of the population reporting any unmet need. ${ }^{48}$ Evidence suggests, however, that not all mental health supports received result in met need, with a recent Canadian study noting significant improvements in met needs when individuals sought mental health care from primary or specialist care, but not from informal supports only. ${ }^{45}$

Our study has several strengths. This large representative, population-based sample enabled us to explore trends in mental health and service use over an 11-year period and across multiple sociodemographic groups. We were able to examine both objectively and subjectively measured mental health factors, and we captured physician and nonphysician services, which few studies have explored in the past.

\section{Limitations}

This study has limitations worth noting. First, it relied on selfreported data, which are subject to biases in respondents' recall and reporting. Although this method was necessary for assessing perceived mental health, the accuracy of self-reported use of mental health services is unclear. Second, the CCHS excluded certain groups (e.g., Indigenous populations living on reserve, individuals in the military and those living in institutions) that are known to be at increased risk of mental health problems; ${ }^{49-52}$ inclusion of these groups would likely affect the prevalence of mental health conditions and service use presented in this study. Third, we examined 2 objectively measured conditions; however, we were unable to examine other common disorders, such as anxiety or substance use disorders, that were not consistently collected in the CCHS. Fourth, because of the data availability of the CCHS, our study period was restricted to 2002-2014; thus, rates reported in our study may differ from those found currently. We also acknowledge that the annual rates we present are averages over 12 months and may mask monthly or seasonal trends in our data. Fifth, the definition of mental health services did not allow us to assess whether that care was effective or whether needs were met; future work is needed to explore whether increasing use of mental health services is associated with better outcomes.

\section{Conclusion}

We found that despite a stable prevalence of objectively measured psychiatric disorders, self-reported mental health issues and service use have increased significantly over time. Rising use of mental health services within a health care system already strained with respect to mental health care provision emphasizes the need for continued improvements in equitable access to care.

\section{References}

1. Cook BL, Trinh NH, Li Z, et al. Trends in racial-ethnic disparities in access to mental health care, 2004-2012. Psychiatr Serv 2017;68:9-16.

2. Trends in income-related health inequalities in Canada: technical report. Ottawa: Canadian Institute for Health Information; 2015. Available: https://secure.cihi.ca/ free_products/trends_in_income_related_inequalities_in_canada_2015_en.pdf (accessed 2016 Aug. 4).
3. Hazlett SB, McCarthy ML, Londner MS, et al. Epidemiology of adult psychiatric visits to US emergency departments. Acad Emerg Med 2004;11:193-5.

4. Larkin GL, Claassen CA, Emond JA, et al. Trends in US emergency department visits for mental health conditions, 1992 to 2001. Psychiatr Serv 2005;56:671-7.

5. Mojtabai R, Jorm AF. Trends in psychological distress, depressive episodes and mental health treatment-seeking in the United States: 2001-2012. J Affect Disord 2015;174:556-61.

6. Patten SB, Williams JV, Lavorato $\mathrm{DH}$, et al. The prevalence of major depression is not changing. Can J Psychiatry 2015;60:31-4.

7. Simpson KR, Meadows GN, Frances AJ, et al. Is mental health in the Canadian population changing over time? Can J Psychiatry 2012;57:324-31.

8. Kessler RC, Demler O, Frank RG, et al. Prevalence and treatment of mental disorders, 1990 to 2003. N Engl J Med 2005;352:2515-23.

9. Baxter AJ, Vos T, Scott KM, et al. The global burden of anxiety disorders in 2010. Psychol Med 2014;44:2363-74.

10. de Graaf R, ten Have M, van Gool C, et al. Prevalence of mental disorders and trends from 1996 to 2009. Results from the Netherlands Mental Health Survey and Incidence Study-2. Soc Psychiatry Psychiatr Epidemiol 2012;47:203-13.

11. Spiers N, Bebbington P, McManus S, et al. Age and birth cohort differences in the prevalence of common mental disorder in England: National Psychiatric Morbidity Surveys 1993-2007. Br J Psychiatry 2011;198:479-84.

12. O'Connor EA, Whitlock EP, Gaynes B, et al. Preventive Services Task Force Evidence Syntheses, formerly Systematic Evidence Reviews. In: Screening for depression in adults and older adults in primary care: an updated systematic review. Rockville (MD): Agency for Healthcare Research and Quality; 2009.

13. Pearson C, Janz T, Ali J. Mental and substance use disorders in Canada. Ottawa: Statistics Canada; 2013.

14. Drapeau A, Marchand A, Beaulieu-Prévost D. Epidemiology of psychological distress. Mental Illnesses-understanding, prediction and control. In: L'Abate L, editor. London (UK): IntechOpen; 2012:105-34.

15. Albizu-Garcia CE, Alegría M, Freeman D, et al. Gender and health services use for a mental health problem. Soc Sci Med 2001;53:865-78.

16. Bhavsar V, McGuire P, MacCabe J, et al. A systematic review and meta-analysis of mental health service use in people who report psychotic experiences. Early Interv Psychiatry 2018;12:275-85.

17. Ng TP, Jin AZ, Ho R, et al. Health beliefs and help seeking for depressive and anxiety disorders among urban Singaporean adults. Psychiatr Serv 2008;59:105-8.

18. Olfson M, Marcus SC, Tedeschi M, et al. Continuity of antidepressant treatment for adults with depression in the United States. Am J Psychiatry 2006;163:101-8.

19. Ryan G, Marley I, Still M, et al. Use of mental-health services by Australian medical students: a cross-sectional survey. Australas Psychiatry 2017;25:407-10.

20. Zuvekas SH, Fleishman JA. Self-rated mental health and racial/ethnic disparities in mental health service use. Med Care 2008;46:915-23.

21. Béland Y, Bailie L, Catlin G, et al. CCHS and NPHS - an improved health survey program at Statistics Canada. In: Proceedings of the American Statistical Association Meeting, Survey Research Methods. 2000 Aug. 16;682-687.

22. Beland Y. Canadian community health survey - methodological overview. Health Rep 2002;13(3):9-14.

23. Canadian Community Health Survey Cycle 1.2: mental health and well-being public use microdata file documentation. Ottawa: Statistics Canada; 2002. Available: www23.statcan.gc.ca/imdb-bmdi/document/3226_DLI_D1_T22_ V2-eng.pdf (accessed 2017 Oct. 11).

24. Healthy minds, healthy people: a ten-year plan to address mental health and substance use in British Columbia. Vancouver: Ministry of Health Services and Ministry of Children and Family Development; 2010. Available: www.health. gov.bc.ca/library/publications/year/2010/healthy_minds_healthy_people.pdf (accessed 2017 Sept. 12).

25. Open minds, healthy minds: Ontario's comprehensive mental health and addictions strategy. Queen's Printer for Ontario; 2011. Available: www.health.gov. on.ca/en/common/ministry/publications/reports/mental_health2011/mental health_rep2011.pdf (accessed 2017 Oct. 11).

26. Prochaska JJ, Sung HY, Max W, et al. Validity study of the K6 scale as a measure of moderate mental distress based on mental health treatment need and utilization. Int J Methods Psychiatr Res 2012;21:88-97.

27. Thomas S, Wannell B. Combining cycles of the Canadian Community Health Survey. Health Rep 2009;20:53-58. 
28. Chiu M, Amartey A, Wang X, et al. Ethnic differences in mental health status and service utilization: a population-based study in Ontario, Canada. Can J Psychiatry 2018;63:481-91.

29. Aragonès $E$, Pinol JL, Labad A. The overdiagnosis of depression in nondepressed patients in primary care. Fam Pract 2006;23:363-8.

30. Ghouse AA, Sanches M, Zunta-Soares G, et al. Overdiagnosis of bipolar disorder: a critical analysis of the literature. ScientificWorldJournal 2013;2013: 297087. doi: 10.1155/2013/297087.

31. Klinkman MS, Coyne JC, Gallo S, Schwenk TL. False positives, false negatives, and the validity of the diagnosis of major depression in primary care. Arch Fam Med 1998;7:451-61.

32. Tiemens BG, VonKorff M, Lin EH. Diagnosis of depression by primary care physicians versus a structured diagnostic interview. Understanding discordance. Gen Hosp Psychiatry 1999;21:87-96

33. National mental health policy 2008. Canberra (AU): Australian Government, Department of Health; 2009. Available: www.health.gov.au/internet/publications /publishing.nsf/Content/mental-pubs-n-pol08-toc (accessed 2017 Oct. 23).

34. New investment in mental health services [news]. UK Department of Health and Social Care; 2016 Feb. 15. Available: www.gov.uk/government/news/new -investment-in-mental-health-services (accessed 2017 Oct. 23).

35. Kosidou K, Magnusson C, Mittendorfer-Rutz E, et al. Recent time trends in levels of self-reported anxiety, mental health service use and suicidal behaviour in Stockholm. Acta Psychiatr Scand 2010;122:47-55.

36. Mojtabai R. Americans' attitudes toward mental health treatment seeking: 1990-2003. Psychiatr Serv 2007;58:642-51.

37. Executive summary: a survey about mental health and suicide in the United States. New York: Harris Poll; 2018. Available: https://afsp.org/executive-summary -survey-mental-health-suicide-united-states (accessed 2017 Aug. 16).

38. Attitudes to mental illness 2014 research report: prepared for time to change. London (UK): TNS BMRB; 2015. Available: www.time-to-change.org.uk/sites/default/files/ Attitudes_to_mental_illness_2014_report_final_0.pdf (accessed 2017 Aug. 16).

39. Evans-Lacko S, Brohan E, Mojtabai R, et al. Association between public views of mental illness and self-stigma among individuals with mental illness in 14 European countries. Psychol Med 2012;42:1741-52.
40. Henderson C, Evans-Lacko S, Thornicroft G. Mental illness stigma, help seeking, and public health programs. Am J Public Health 2013;103:777-80.

41. Rüsch N, Evans-Lacko SE, Henderson C, et al. Knowledge and attitudes as predictors of intentions to seek help for and disclose a mental illness. Psychiatr Serv 2011;62:675-8.

42. Barr B, Kinderman P, Whitehead M. Trends in mental health inequalities in England during a period of recession, austerity and welfare reform 2004 to 2013. Soc Sci Med 2015;147:324-31.

43. Roll JM, Kennedy J, Tran M, et al. Disparities in unmet need for mental health services in the United States, 1997-2010. Psychiatr Serv 2013;64:80-2.

44. Tiwari SK, Wang J. Ethnic differences in mental health service use among white, Chinese, South Asian and South East Asian populations living in Canada. Soc Psychiatry Psychiatr Epidemiol 2008;43:866-71.

45. Urbanoski K, Inglis D, Veldhuizen S. Service use and unmet needs for substance use and mental disorders in Canada. Can J Psychiatry 2017;62:551-9.

46. Walker ER, Cummings JR, Hockenberry JM, et al. Insurance status, use of mental health services, and unmet need for mental health care in the United States. Psychiatr Serv 2015;66:578-84.

47. Wang PS, Lane M, Olfson M, et al. Twelve-month use of mental health services in the United States - results from the National Comorbidity Survey Replication. Arch Gen Psychiatry 2005;62:629-40.

48. Meadows GN, Bobevski I. Changes in met perceived need for mental healthcare in Australia from 1997 to 2007. Br J Psychiatry 2011;199:479-84.

49. Mulvale G, Abelson J, Goering P. Mental health service delivery in Ontario, Canada: How do policy legacies shape prospects for reform? Health Econ Policy Law 2007;2(pt 4):363-89.

50. Hawthorne WB, Folsom DP, Sommerfeld DH, et al. Incarceration among adults who are in the public mental health system: rates, risk factors, and short-term outcomes. Psychiatr Serv 2012;63:26-32.

51. Greene-Shortridge TM, Britt TW, Castro CA. The stigma of mental health problems in the military. Mil Med 2007;172:157-61.

52. Nelson SE, Wilson K. The mental health of Indigenous peoples in Canada: a critical review of research. Soc Sci Med 2017;176:93-112.
Competing interests: Simone Vigod receives royalties from UpToDate for authorship of materials related to depression and pregnancy. No other competing interests were declared.

This article has been peer reviewed.

Affiliations: Mental Health and Addictions Research Program (Chiu, Amartey, Wang, Vigod, Kurdyak), ICES; Institute of Health Policy, Management and Evaluation (Chiu, Vigod, Kurdyak), Dalla Lana School of Public Health, University of Toronto; Women's College Hospital and Research Institute (Vigod); Department of Psychiatry, Faculty of Medicine (Vigod, Kurdyak), University of Toronto; Social and Epidemiological Research Department (Kurdyak), Institute for Mental Health Policy Research, Centre for Addiction and Mental Health, Toronto, Ont.

Contributors: Maria Chiu was the principal investigator, conceived and designed the study, and provided project oversight. Maria Chiu and Abigail Amartey drafted the manuscript. Xuesong Wang performed the statis- tical analyses. Maria Chiu, Abigail Amartey, Xuesong Wang, Simone Vigod and Paul Kurdyak interpreted the data, critically revised the manuscript for important intellectual content, approved the final version to be published, and agreed to be accountable for all aspects of the work. Xuesong Wang had full access to all the data in the study and takes responsibility for the integrity of the data and the accuracy of the data analysis.

Data sharing: The data set from this study is held securely in coded form at ICES. While data-sharing agreements prohibit ICES from making the data set publicly available, access may be granted to those who meet prespecified criteria for confidential access, available at www.ices.on.ca/DAS. The full data set creation plan and underlying analytic code are available from the authors on request, understanding that the computer programs may rely on coding templates or macros that are unique to ICES and are therefore either inaccessible or may require modification.
Acknowledgements: The authors acknowledge that the data used in this publication are from Statistics Canada's Ontario components of the Canadian Community Health Surveys from 2002 to 2014. They thank all the participants of these surveys and the staff from Statistics Canada who assisted in the survey data collection and management.

Disclaimer: This study was supported by ICES, which is funded by an annual grant from the Ontario Ministry of Health and LongTerm Care (MOHLTC). The opinions, results and conclusions reported in this paper are those of the authors and are independent from the funding sources. No endorsement by ICES or the Ontario MOHLTC is intended or should be inferred.

Accepted: Feb. 18, 2020

Correspondence to: Maria Chiu, maria.chiu@ices.on.ca 